\title{
Impact of Patch Testing on Quality of Life in Patients with Hand Eczema: A Follow-up Study
}

\section{Agrawal $S,{ }^{1}$ Rijal A, ${ }^{1}$ Bhattarai $S^{2}$}

\author{
Department of Dermatology and Venereology \\ ${ }^{1}$ B. P. Koirala Institute of Health Sciences, Dharan \\ ${ }^{2}$ Kathmandu Medical College and teaching Hospital \\ Kathmandu \\ Nepal
}

\section{Corresponding Author}

Sudha Agrawal

Department of Dermatology and Venereology

B. P. Koirala Institute of Health Sciences

Dharan, Nepal

Email: sudha92@yahoo.com

\section{Citation}

Agrawal S, Rijal A, Bhattarai S. Impact of Patch Testing on Quality of Life in Patients with Hand Eczema: A Follow-up Study. Kathmandu Univ Med J 2013;43(3):216-220.

\section{ABSTRACT}

\section{Background}

Patch testing has previously been shown to influence the quality of life, although a very few studies have shown if this is dependent on the result of the patch tests.

\section{Objective}

To assess the impact of patch testing on the quality of life $(\mathrm{QOL})$ in patients with hand eczema (HE).

\section{Methods}

A total of 50 patients diagnosed of hand eczema at the time of patch testing, aged 16 years and above participated in this study. Detailed demographic information and diagnosis of hand eczema were collected on the day of the patch test. After six weeks, the patients were asked about the hand eczema, knowledge of their allergies and change in their life style to avoid the relevant allergens demonstrated on the patch test. Dermatology Life Quality Index (DLQI) was used to measure the QOL on both occasions.

\section{Results}

The patch test positivity was found in $68 \%$ of patients to one or more allergens. The sum score of DLQI at baseline was $12.16 \pm 5.58$ with median 12.0. HE had most impact on symptoms and feelings. Patients with both positive patch test (mean baseline= 11.94 \pm 5.88; mean at six weeks $=2.81 \pm 2.01 ; \mathrm{P}<0.001$ ) and negative patch test (mean baseline $=12.63 \pm 5.03$; mean at 6 weeks $=5.4 \pm 3.56 ; \mathrm{P}=0.001$ ) showed significant improvement in DLQI scores, however it was more improved in patients with positive patch test than in patients with negative patch test.

\section{Conclusions}

Hand eczema had an appreciable impact on the QOL. Patch testing had been beneficial to most patients in improving patient quality of life considerably.

\section{KEY WORDS}

Dermatology life quality index (DLQI), hand eczema, patch test, quality of life (QOL)

\section{INTRODUCTION}

Hand eczema (HE), a common distressing condition, perplexes both the patients as well as the physician. ${ }^{1}$ The prevalence of $\mathrm{HE}$ among general population is estimated to be about $2-10 \%$ and it accounts for $21-34 \%$ of all types of eczema in various hospital-based studies. ${ }^{2,3}$ It is a multifactorial disease in which both exogenous and endogenous factors play a role. A complex interplay of exogenous risk factors such as several irritants and /or multiple well-known and unknown allergens and of the endogenous disposition is believed to be responsible for the occurrence and the course of HE in humans. Clinically, it is often difficult to distinguish allergic contact dermatitis (ACD) from irritant contact dermatitis and endogenous dermatitis. Therefore patch testing is the fundamental for the correct diagnosis of ACD. ${ }^{4}$

Hand eczema often results in ongoing disease and disability. A significant proportion of individuals experience work disruption including loss of employment or job changes and often results in economic burden on society. ${ }^{5}$ It affects patients' quality of life (QOL). A few studies in the literature have shown that the quality of life depends on the result of the patch tests, but no such study has been undertaken in Indian subcontinent. ${ }^{6-9}$ The aim of the present study was 
to assess the impact of patch testing on the quality of life (QOL) in patients with hand eczema attending a tertiary care centre of eastern Nepal.

\section{METHODS}

All clinically diagnosed cases of hand eczema attending the Dermatology Out Patient Department of B. P. Koirala Institute of Health Sciences, Dharan over a period of one year constituted the study population with the following exclusion criteria: age less than 16 years; fungal infection anywhere in the body confirmed by the $\mathrm{KOH}$ mount; bacterial infection anywhere in the body on clinical examination; irritant or allergic contact dermatitis elsewhere in the body by history and clinical examination; patients on drugs known to cause vesicular eruptions on the palms and soles; patients suspected to be suffering from cumulative insult dermatitis and refusal for patch testing

A prior informed consent was taken from all the patients. A detailed history of each patient was recorded in the proforma designed for the study. Demographic information, distribution of the eruption, job, duration of hand eczema and type of hand eczema were collected on the day of the patch test. A history of atopy in self or family members, any history of known allergy to food, drug or any agent, hobbies and part time activities were also recorded.

Patch test was done using the Indian Standard Series of Allergens including plant Allergens as approved by the Contact and Occupational Dermatoses Forum of India (CODFI). After patch testing, patients were treated based on acute, sub-acute and chronic lesions accordingly with the well-accepted methods. , $^{3,4}$ Patients were also educated on (i) trying their best to avoid any known allergic materials and any predisposing or exacerbating factors and (ii) washing hands as instructed in skin care. ${ }^{4}$ After six weeks, the patients were asked about the hand eczema after patch test, knowledge of their allergies and change in their life style to avoid the relevant allergens demonstrated on patch test.

\section{Quality of life at baseline and 6 weeks after patch testing}

The QOL was measured by using Dermatology Life Quality Index (DLQI) on both occasions. ${ }^{10}$ The questionnaire was translated into Nepali Language using translation methodology. One enumerator with intermediate qualification was hired to help in data collection. The enumerator distributed the pre-tested questionnaire on both occasions to hand eczema patients. The questions were classified according to 6 headings items: Symptoms and feelings (SF = questions 1 and 2), daily activities (DA = questions 3 and 4$)$, leisure $(L=$ questions 5 and 6$)$, work and school ( $\mathrm{W}=$ question 7$)$, personal relationships ( $P R=$ questions 8 and 9$)$, and treatment ( $T$ = question 10$)$.

\section{Scoring system}

Scoring

Questions were scored on a 4-point Likert's type scale with $0=$ "not at all" to 3 = "very much". The scoring of each question was as follows: Very much scored-3; A lot scored- 2; A little scored- 1; Not at all scored (0) and Not relevant scored (0). The total score was calculated based on instructions obtained from Finlay et al(1990). ${ }^{10}$ The total score was calculated by summation of the scores for each item with a maximum of 30 and a minimum of 0 (zero).

Meaning of DLQI Scores: A high score indicates a greater impairment to QOL. ${ }^{10}$ The score $0-1$ has no effect at all on patient's life; score 2-5 has mild effect on patient's life; score 6-10 has moderate effect on patient's life; score11-20 has very large effect on patient's life and score $21-30$ has extremely large effect on patient's life.

Sample Size: A total of 50 patients of hand eczema were enrolled in this study to detect the difference in mean of 2 between two groups considering the pooled standard deviation 3.5, a 5\% error (two-sided), 80\% power and a drop out rate of $5 \%$.

The collected data were entered in a computer. A computer program was prepared for data entry. One of the investigators supervised the computer operator during data entry to minimize the error. SPSS software 10.0 was used for data tabulation and analysis. To know the test of significance Wilcoxon's rank sum test and Wilcoxon's sign rank test were used.

\section{RESULTS}

Of the total 50 cases of hand eczema, forty six patients completed the study while 4 patients were lost to follow up. Fig 1 shows the flow diagram of participants in the study. The mean age of the patients included in the study was $34.58 \pm 12.86$ years. Gender distribution of the study population was $20(40.00 \%)$ males and 30 (60.0\%) females. The age and sex distribution of study population is depicted in fig 2 . The mean duration of illness was 36.442 \pm 37.46 months with a median of 12 months. In our study we had patients with different occupations. Most of them were housewives (32.0\%) followed by students (16.0\%),

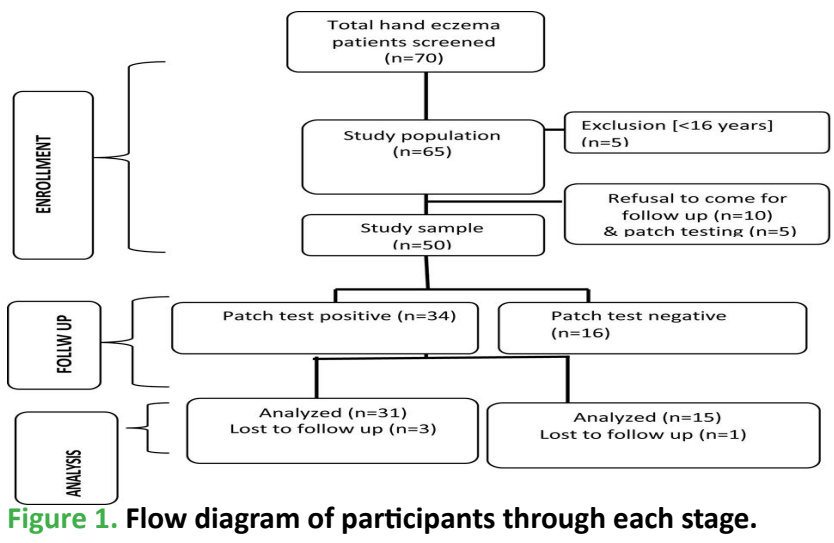




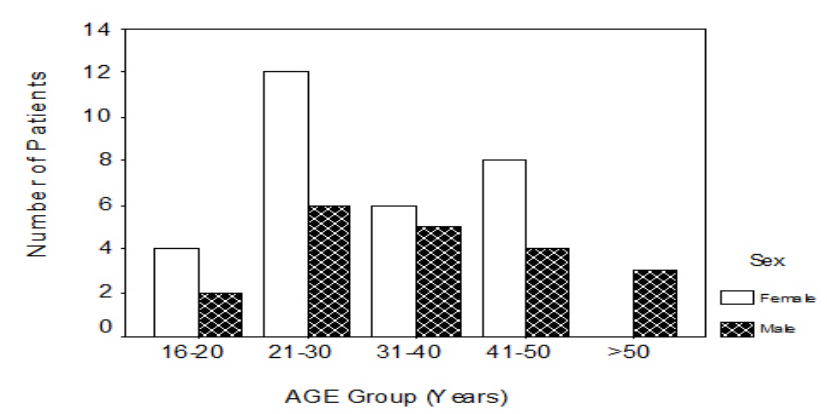

Figure 2. Age and sex distribution of patients with hand eczema.

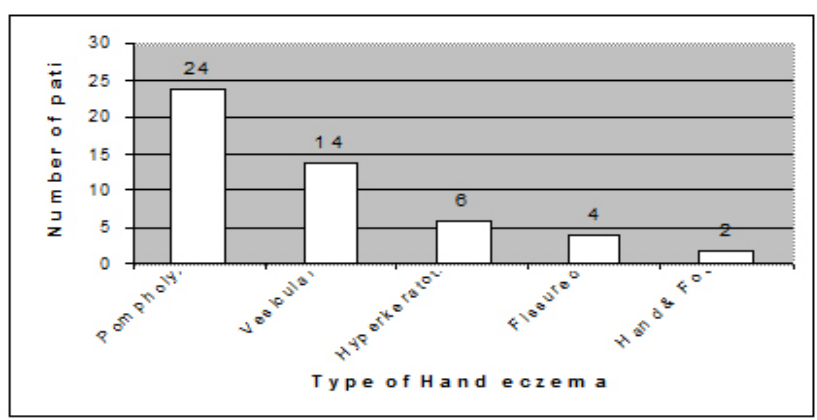

Figure 3. Morphological classification of Hand eczema.

government employer (16.0\%), staff-nurses (12.0\%), businessmen $(10.0 \%)$, farmer $(6.0 \%)$, mason $(4.0 \%)$ and dentists $(4.0 \%)$.

The distributions of the study population, according to the type of hand eczema, are shown in the figure 3 . The most frequent hand eczema was pompholyx 24(48.0\%) followed by vesicular type $14(28.0 \%)$ and hyperkeratotic type 6 (12.0\%).

Thirty four (68\%) patients had ACD confirmed with patch test to at least 1 allergen. Nickel sulphate was the most common sensitizer; positive in 20 patients (18.5\%) followed by gentamicin (7) and cobalt chloride (7). Four (11.1\%) patients each were positive for mercapto mix and fragrance mix (Table 1). Table 2 depicts the association of patch test positivity and types of hand eczema and it was found to be more common in vesicular hand eczema.

Table 1 . Common allergen in patients with positive patch test (n=34).

\begin{tabular}{|lc|}
\hline \multicolumn{1}{c}{ Allergen } & No of Patients (\%) \\
\hline Nickel sulphate & $20(58.8 \%)$ \\
\hline Gentamicin & $7(20.5 \%)$ \\
\hline Cobalt chloride & $7(20.5 \%)$ \\
\hline Fragrance mix & $4(11.8 \%)$ \\
\hline Mercapto mix & $4(11.8 \%)$ \\
\hline Potassium dichromate & $3(8.8 \%)$ \\
\hline 4-Phenylenediamine & $3(8.8 \%)$ \\
\hline Epoxy resin & $1(2.9 \%)$ \\
\hline Neomycin sulphate & $1(2.9 \%)$ \\
\hline Parabens & $1(2.9 \%)$ \\
\hline Formaldehyde & $1(2.9 \%)$ \\
\hline Balsam of peru & $1(2.9 \%)$ \\
\hline
\end{tabular}

Table 2. Patch test positivity and type of hand eczema.

\begin{tabular}{|c|c|c|c|c|c|c|}
\hline \multirow[t]{2}{*}{ Diagnosis } & \multicolumn{3}{|c|}{ Result of Patch test } & \multirow{2}{*}{$\begin{array}{c}\text { Chi- } \\
\text { square }\end{array}$} & \multirow[t]{2}{*}{ DF } & \multirow{2}{*}{$\begin{array}{c}P \\
\text { value }\end{array}$} \\
\hline & Negative & $\begin{array}{l}\text { Posi- } \\
\text { tive }\end{array}$ & Total & & & \\
\hline $\begin{array}{l}\text { Fissured/Hand } \\
\text { and Foot/ hy- } \\
\text { perkeratotic }\end{array}$ & 2 & 10 & 12 & \multirow{4}{*}{10.691} & \multirow{4}{*}{2} & \multirow{4}{*}{0.003} \\
\hline Pompholyx & 13 & 11 & 24 & & & \\
\hline Vesicular & 1 & 13 & 14 & & & \\
\hline Total & 16 & 34 & 50 & & & \\
\hline
\end{tabular}

Opinion of patch testing at the baseline and 6 weeks follow up

The average time spent advising each patient on the results of patch testing was 20 minutes. Fifty two percent patients felt that patch test had been helpful, $46 \%$ had no particular opinion on the value of patch testing and $2 \%$ patients stated that it was not helpful. From the $2^{\text {nd }}$ questionnaire taken 6 weeks after patch testing, $87 \%$ patients with ACD reported either improvement or clearing of their skin condition and $79 \%$ patients mentioned that patch testing had been helpful while $42.8 \%$ of patch test negative patients also thought it was beneficial.

\section{Quality of Life at the base line patch testing visit}

Of the 50 DLQI forms that were distributed, a total of 48 patients (96\%) answered all 10 questions while 2 patients (4\%) answered only 9 questions. The sum scores showed varying QOL impairment with a mean of $12.16 \pm 5.58$ (range 2-27, median 12.00). Fifty eight percent of our patients had a DLQI score of 11 or more, out of a maximum score of 30.

There was no statistically significant difference in distribution between females $12.16 \pm 5.43$ and males 12.15 \pm 5.9 . The sum score of DLQI in age group up to 40 years and greater than 40 years were $11.96 \pm 5.00$ and $12.5 \pm 6.62$ respectively and it did not reveal any significant difference ( $W=810.000, Z=-0.122, P=0.0903)$. Within the categories, no statistically significant gender differences were seen however patients of less then 40 years had considerable effects on work/school category ( $W=338.000 \quad Z=-2.539$, $\mathrm{P}=0.011$ ). The comparison of overall score and subscales scores in patients having positive patch test and negative patch test results was not statistically different. The DLQI in different types of hand eczema was also not statistically significant. For testing age, sex, type of hand eczema and patch test effects, a logistic regression analysis was used. It revealed neither significant main effect of age, gender and type of hand eczema nor patch test effects on DLQI dichotomized total score.

\section{Impact of patch testing on DLQI after 6 weeks of follow up}

There was a significant improvement in the DLQI score in all patch- tested individuals at six weeks (median 3, Z=-5.834; $\mathrm{P}<0.001$ ). Table 3 depicts total DLQI scores at baseline and 6 weeks later according to the result of patch testing. Patients with both positive patch test (mean baseline $=11.94 \pm 5.88$; 
Table 3. Total DLQI Scores at baseline and 6 weeks later according to the result of patch testing.

\begin{tabular}{|c|c|c|c|c|c|c|c|}
\hline $\begin{array}{l}\text { Patch } \\
\text { test } \\
\text { results }\end{array}$ & & $\begin{array}{c}\text { At } \\
\text { base- } \\
\text { line }\end{array}$ & $\begin{array}{c}6 \\
\text { weeks }\end{array}$ & $\begin{array}{l}\text { Wil- } \\
\text { coxon's } \\
\text { sign } \\
\text { Z }\end{array}$ & $\begin{array}{c}P \\
\text { value }\end{array}$ & $\begin{array}{l}\text { Wil- } \\
\text { cox- } \\
\text { on's } \\
\text { rank } \\
\text { sum Z }\end{array}$ & $\begin{array}{c}P \\
\text { value }\end{array}$ \\
\hline \multirow{3}{*}{$\begin{array}{l}\text { Posi- } \\
\text { tive } \\
(\mathrm{N}=31)\end{array}$} & Mean & 11.94 & 2.81 & \multirow{3}{*}{-4.786} & \multirow{3}{*}{0.001} & \multirow{6}{*}{-2.909} & \multirow{6}{*}{0.004} \\
\hline & $\begin{array}{l}\text { Me- } \\
\text { dian }\end{array}$ & 11.00 & 3.00 & & & & \\
\hline & SD & 5.88 & 2.01 & & & & \\
\hline \multirow{3}{*}{$\begin{array}{l}\text { Nega- } \\
\text { tive } \\
(\mathrm{N}=15)\end{array}$} & Mean & 12.63 & 5.40 & \multirow{3}{*}{-3.353} & \multirow{3}{*}{0.000} & & \\
\hline & $\begin{array}{l}\text { Me- } \\
\text { dian }\end{array}$ & 13.0 & 5.00 & & & & \\
\hline & SD & 5.03 & 3.58 & & & & \\
\hline
\end{tabular}

mean at six weeks $=2.81 \pm 2.01 ; \mathrm{P}<0.001$ ) and negative patch test (mean baseline $=12.63 \pm 5.03$; mean at six weeks $=5.4 \pm$ 3.56; $P=0.001$ ) showed significant improvement in DLQI scores, however it was more improved in patients with positive patch test than in patients with negative patch test.

\section{DISCUSSION}

HE is usually disabling and distressing to the sufferer and often difficult to treat. This difficulty is not only due to the intrinsic nature of the eczema itself and the special anatomical features of the palmar skin but also because of the role of the hands in everyday social life and work and the inability of the patients to comply fully with avoidance techniques. ${ }^{4}$

Hand eczema is twice as common in females as in males and is most common in young females before the age of 40 years. ${ }^{11}$ In our study, there were $30(60 \%)$ females and $20(40 \%)$ males, with a female to male ratio of $1.5: 1$. The reason for this sex difference could be due to the greater exposure of women to wet work and surfactants and more often exposed to metals and perfumes. ${ }^{12,13}$ Similar to the various studies, the majority of the patients in the present study were reported to be less than 40 years. ${ }^{3,11}$

Hand eczema is a long lasting disease with a mean duration of 12 years from the first appearance to the time of examination. ${ }^{4}$ It is a disease with a relapsing and remitting course. The average duration of illness in our study was 36.44 months (range 1 month to 120 months). The shorter duration of illness in our patients could be due to the severe non-remitting cases reporting to a tertiary care hospital like our institute.

$\mathrm{HE}$ is a multifactorial disease in which both exogenous and endogenous factors play a vital role. A complex interplay of exogenous risk factors such as several irritants and /or multiple well-known and or/unknown allergens and of the endogenous disposition is believed to be responsible for the occurrence and the course of HE. ${ }^{4}$ Clinically Li and Wang divided HE into 5 groups: (1) vesicular form, (2) fissured form, (3) hyperkeratotic form, (4) hand and foot dermatitis and (5) pompholyx.14 Pompholyx accounted for 5-26.9\% of all cases of hand eczema while hyperkeratotic hand eczema was reported in about 6.7\%.14, 15 In our study most of the patients were diagnosed as having pompholyx (48\%) followed by vescicular (28\%), hyperkeratotic $(12 \%)$, fissured $(8 \%)$ and hand and foot (4\%) type of $\mathrm{HE}$. Pompholyx, considered to be more symptomatic, recurrent and severe than the other hand ezcemas, could explain the greater number of patients seeking medical treatment in our study.

Patch testing has proved to be a useful tool for the detection of allergic contact dermatitis and identification of contact allergens. When positive reactions correlate with environmental exposure, the test usually assists the physician in establishing the cause of eczema. The Positive Patch Test Result (PPTR) however shows variation from 9.8\% $-72.88 \% .^{2,16,17}$ Similar to Anger et al the patch test positivity was found in $68 \%$ of patients in our study. ${ }^{18}$

More than half of the patients with the vesicular form of HE showed positive PT results, supporting the hypothesis that most of vesicular $\mathrm{HE}$ is allergic contact dermatitis.14 Previous studies have shown $28 \%-50 \%$ patients with pompholyx have positive patch test with the standard series. ${ }^{3,13}$ This is comparable with the results in the present study as well where a positivity of $45 \%$ was seen. However, $50 \%$ of patients with the fissured form of $\mathrm{HE}$ also gave positive results, indicating that, contact hypersentivity may also play a role in fissured HE which is usually due to skin irritation. ${ }^{3}$ It was also found in the hyperkeratotic form of HE.

Contact allergens are also important as HE may be precipitated by contact with chemicals that elicit an allergic reaction. ${ }^{15}$ Chemicals responsible for such an allergic contact reaction can penetrate the skin easily due to their very small molecular weight and lipid solubility and can react with cutaneous proteins to form complete antigens. In a study done on Swedish dentist with hand eczema, patch testing was positive in $94 \%$ and the most frequent allergens were nickel sulfate, fragrance mix and thiuram mix while another study revealed chromate, rubber chemicals and nickel as the common allergens. ${ }^{16,17}$ The mechanism of hand eczema associated with nickel allergy may be direct exposure of the hands as well as systemic contact dermatitis caused by transcutaneous absorption or both. $^{2}$ In our study also PPTR (Positive Patch Test Result) was found in 34 (68\%) subjects to 1 or more allergens. The most common allergen was nickel sulphate followed by gentamicin and cobalt chloride.

After six weeks our results showed, $87 \%$ of those with ACD had either improvement or clearing of their skin condition and indicated that patch testing has been beneficial (79\%). Nethercott et al also reported that the highest number of patients cleared dermatitis at the time of the follow up. ${ }^{19}$ The higher benefit reported may be attributed to the shorter interval between patch testing and completion 
of the $2^{\text {nd }}$ questionnaire as reported by Woo et al in their study. Among those with negative results, the patch testing was also found to be helpful (42.8\%). ${ }^{6}$ This might have resulted because these patients also received general reinforcement of the use of emollients and skin protection. Education plays an important role in the management of patients with $A C D$ and proper information improves compliance with the advice given. ${ }^{16,20}$ Higher benefit in our study could be due to the reason that the average time spent in advising each patient on the results of patch testing was 20 minutes.

It is well known that many skin diseases can have an impact on quality of life. It may be greater where the skin disease is more extensive, more obvious to others or interfere with the ability to perform everyday activities. Hand involvement has a considerable impact on QOL. ${ }^{8}$ In our study also, the sum scores of DLQI was found to be $12.16 \pm 5.58$ with median 12.0 however, there was no correlation between mean DLQI score at baseline and age, sex, duration, type of hand eczema and results of patch test similar to the study reported..$^{21} \mathrm{HE}$ had its most impact on symptoms and feelings. This has also been shown in occupational dermatitis and atopic eczema. . $1,22^{2}$

Rajagopalan et al and Thomson et al reported an improved

\section{REFERENCES}

1. Duarte I, Terumi NJ, Lazzarini R. Hand eczema: evaluation of 250 patients. Am J Contact Dermat. 1998; 9: 216- 233.

2. Nielsen HN, Linneberg A, Menne T, Madsen F. The association between contact allergens and hand eczema in 2 cross sectional surveys 8 years apart. Contact Dermatitis. 2002; 46: 71-77.

3. Burton JL, Holden CA. Eczema, lichenification and prurigo. In: Textbook of Dermatology. 6th edition. Champion R H, Burton J L, Burns D A, Breathnach S M (eds). Oxford: Blackwell Science Ltd; 1998: pp. 629-667.

4. Agner T. Hand eczema. In: Textbook of Contact Dermatitis. 4th edition. Frosch P J, Menné T, Lepoittevin J-P (eds). Berlin Heidelberg : Springer Verlag; 2006. pp. 335-345.

5. Medling B, Swanbeck G. Consequences of having hand. Contact Dermatitis. 1990; 23: 6-14.

6. Woo PN, Hay IC, Ormerod AD. An audit of the value of patch testing and its effect on quality of life. Contact Dermatitis .2003; 48: 244-247.

7. Rajagopalan R, Anderson RT. Impact of patch testing on dermatology specific quality of life in patients with allergic contact dermatitis. Am J Contact dermat. 1997; 8: 215-221.

8. Holness DL. Results of quality of life questionnaire in a patch test clinic population. Contact Dermatitis 2001; 44: 80-84.

9. Thomson KF, Pollock B, Sommer S, Wilkinson SM. The effect of patch testing on quality of life. Br J Dermatol. 2002; 147: 266-269.

10. Finlay AY, Khan GK, Luscombe DK, Salek MS. Validation of sickness impact profile and psoriasis disability index in psoriasis. Br J Dermatol 1990; 123: 751-756.

11. Thyssen JP, Johansen JD, Linneberg A, Menné T. The epidemiology of hand eczema in the general population--prevalence and main findings. Contact Dermatitis. 2010;62(2):75-87. quality of life in patients with ACD after patch testing. ${ }^{7,9}$ Similar to their study we also found the improvement in quality of life in our study (DLQI mean at 6 weeks= 3.65 \pm 2.85, $\mathrm{p}=0.000)$. The $\mathrm{QOL}$ in patients with negative patch test results had also shown improvement in comparison to the baseline score but there was less improvement (5.00) in contrast to those who had positive patch tests (3.00).

\section{CONCLUSION}

In summary, hand eczema had an appreciable impact on the QOL. Patch testing had been beneficial to most patients and it had improved patient's QO. Patch testing helps in early diagnosis of the etiology of contact dermatitis and treat the disease before it becomes chronic, thus, reducing the resources used and improving patient quality of life extensively.

\section{ACKNOWLEDGEMENT}

We express our sincere gratitude to Prof AY Finlay for allowing us to develop the Nepali version of DLQI and granted to use it in this study. We also acknowledge BPKIHS for the funding of this study.

12. Epstein E. Hand Dermatitis: Practical management and current concepts. J Am Acad Dermatol. 1984; 10: 395- 424.

13. Thelin I, Agrup G. Pompholyx- a one-year series. Acta Derm Venerol 1985; 65: 214-217.

14. Li L, Wang J. Contact hypersensitivity in hand dermatitis. Contact Dermatitis. 2002; 47: 206-209.

15. Medling B, Swanbeck G. Epidemiology of different types of hand eczema in an industrial city. Acta Derm Venereol. 1989; 69: 223-227.

16. Goon AT, Goh LC. Epidemiology of occupational skin disease in Singapore 1989-1998. Contact Dermatitis. 2000; 43: 133-136.

17. Wallenhammar LM, Ortengren $U$, Andreasson L, Barregard L,Bjorkner B, Karlsson S, et al. Contact allergy and hand eczema in Swedish Dentists. Contact Dermatitis. 2000; 43: 192-199.

18. Agner T, Anderson KE, Brandao FM, Bruynzeel DP, Bruze M, Frosch $P$, et al. Contact sensitization in hand eczema patients-relation to subdiagnosis, severity and quality of life: a multi-centre study. Contact Dermatitis. 2009; 61: 291-296.

19. Nethercott JR, Holness DL. Disease outcome in workers with occupational skin disease. J Am Acad Dermatol. 1994; 30: 569-574.

20. Jury CS, Forsyth $A$. Compliance and the role of nurses in contact dermatitis. Clinical experimental Dermatol. 2002; 27:253

21. Hutchings CV, Shum KW, Gawkrodger DJ. Occupational contact dermatitis has an appreciable impact on quality of life. Contact Dermatitis. 2001; 45: 17-20.

22. Shum KW, Lawton S, Williams HC, Docherty G, Jones J. The British Association of Dermatologists audit of atopic eczema management in secondary care Phase 3: audit of service outcome. Br J Dermatol 2000; 142: 721-727. 